\title{
Perfil dos idosos em uma área de abrangência da Estratégia Saúde da Família
}

These Abstract

\section{The profile of the elderly in an area within the scope of the Family Health Strategy}

Adriano Luiz da Costa Farinasso

\section{Resumo}

O envelhecimento saudável, com vistas à manutenção da capacidade funcional, deve ser o foco das políticas sociais e de saúde para os idosos. Neste contexto, a instrumentalização das equipes de saúde da família para atender esta emergente parcela populacional deve ser vista como primordial para a consolidação do sistema formal de apoio ao idoso. Assim, este estudo objetivou caracterizar um grupo de idosos velhos (75 anos e mais de idade), residentes na área de abrangência da Estratégia de Saúde da Família (ESF) do município de Jandaia do Sul-PR, quanto ao perfil sóciodemográfico e de saúde. A amostra estudada foi obtida pelo sorteio aleatório de $20 \%$ da população de idosos com 75 anos e mais de idade, residentes na zona urbana de abrangência da ESF. A coleta foi realizada no domicílio dos idosos utilizando uma adaptação do Older Americans Resources and Services (OARS). Foram estudados 86 idosos com média de idade de 82,02 anos; 51,2\% eram do sexo feminino; a média de filhos foi de 5,71; 39,5\% eram analfabetos e 39,4\% trabalhavam em atividades relacionadas à agricultura. Em relação à saúde, 77,9\% eram independentes; 83,7\% autoavaliaram a saúde entre "regular" e "boa"; 76,7\% apresentavam co-morbidades e, a principal rede de apoio relatada foram os filhos. O estudo revelou a importância da adoção de medidas preventivas e promocionais de saúde pelas equipes de saúde da família, na garantia de apoio formal para o idoso e sua família.

Dissertação de Mestrado 2005. Universidade De São Paulo/ Ribeirão Preto - Enfermagem Fundamental

\section{Disponivel para consulta em:}

http://servicos.capes.gov.br/capesdw/resumo.html?idtese=200533633002029017P5

Palavras-chave: Saúde do idoso; saúde da família; Perfil de saúde.
Key Words: health of the elderly, family

health, health profile. 